\title{
СОКРАЩЕНИЕ СРОКОВ ОСВОЕНИЯ СКВАЖИНЫ ПОСЛЕ ПРОВЕДЕНИЯ ГИДРОРАЗРЫВА ПЛАСТА
}

Верисокин A.E. «Северо-Кавказский федеральный университет,

Институт нефти и газа»,

г. Ставрополь, Россия, verisokin.aleksandr@mail.ru

Введение:

В данной статье рассмотрены проблемы, связанные с выносом проппанта, механических частиц породы, неразложившейся жидкости из трещины гидроразрыва пласта в скважину. Актуальность исследования обусловлена необходимостью совершенствования технологии освоения скважин после проведения гидравлического разрыва пласта. Цель статьи заключалась в разработке комплекса устройств, используемых для промывки перфоканалов и стенок скважины в интервале перфорации после осуществления гидроразрыва пласта. Материалы и методы исследований: при написании статьи использованы методы сопоставления и анализа отечественной и зарубежной нефтегазовой литературы, материалы патентных разработок, имеющих опыт применения технологии гидравлического разрыва пласта на нефтегазовых объектах. Результаты исследований и их обсуждение: Выявлена и обоснована необходимость разработки устройства для промывки интервала перфорации. Показано, что затвердевшие и вязкоупругие частички геля попадают в перфорационные отверстия и налипают на стенки каналов и скважины. В дальнейшем эти зоны отложений геля снижают проницаемость в перфоканалах. На основе проведенного исследования автором разработана конструкция устройства для декольматации, позволяющая сократить сроки освоения скважин с такими осложнениями после гидравлического разрыва пласта. Чтобы повысить производительность рассматриваемых скважин, необходимо промыть их представленным устройством в режиме максимального приближения к отложениям. Для лучшего выноса частиц на поверхность предлагается использовать пенные системы, генерируемые струйным насосом, который описан в данной статье.

Выводы:

разработан комплекс устройств, используемых для промывки перфоканалов и стенок скважины в интервале перфорации, который позволит в несколько раз сократить сроки освоения скважин после осуществления гидроразрыва пласта. Описываемые устройства защищены патентами Российской Федерации: Патент на изобретение № 2651869, «Устройство для декольматации скважин», заявка № 2017109500; Патент на изобретение №2643882, «Струйный насос», заявка № 2017114222.

Ключевые слова: гидроразрыв пласта, скважина, перфоканал, проппант, устройство для декольматации, полимер, пена, струйный насос. 
Verisokin A.E. North-Caucasus Federal University, Stavropol, Russia

\section{REDUCTION OF WELL STIMULATION PERIOD AFTER HYDRAULIC FRACTURING}

Introduction:

Investigation tools and methods:

The problems arising from backflow of proppant, rock particles and non-decomposed liquid from hydraulic fractures are considered in the paper. The urgency of the research is caused by the necessity of improvement of well stimulation technology after hydrofracturing. The objective of the paper consists in the development of a set of devices for flushing perforation channels and wellbore walls in the perforation interval after hydrofracturing of a formation.

When writing the paper, the methods of comparison and analysis of national and foreign references in petroleum engineering, patents related to application of formation hydrofracturing were used.

Results and discussion:

The urgency of developing a device for flushing out of perforated intervals is revealed and substantiated. It is shown that solidified viscoelastic particles of gel enter perforation tunnels and stick to their walls and to the wall of a well. Later these zones of gel particles deposits decrease permeability in perforation tunnels. On the basis of the investigations, the author developed a device for well bottomhole cleanout that reduces stimulation period for the wells with the above described problems arising after hydrofracturing. To increase productivity of such wells it is necessary to flush out them applying the developed device in the mode of the closest approach to the deposition zones. For better particles lifting to the surface, it is proposed to use foam systems produced by a jet pump which is described in the paper.

Conclusion. The set of devices for flushing perforation channels and wellbore walls in the perforation interval which allow for multiple decrease of well stimulation period after hydrofracturing is developed. The described devices are protected by the patents of the Russian Federation: patent for invention No 2651869 "A device for cleanout", application for patent № 2017109500; patent for invention № 2643882 "Jet pump", application for patent № 2017114222.

Key words:

hydraulic fracturing, well, perforation tunnel, proppant, device for cleanout, polymer, foam, jet pump.

\section{Введение}

На сегодняшний день в мире все большее внимание уделяется разработке трудноизвлекаемых запасов. К таким запасам можно отнести нефть достаточно плотных пород, которая залегает в слабопроницаемых коллекторах. При этом акцент делается на внедрение новых технологий интенсификации добычи, которые успешно себя зарекомендовали на нефтяных месторождениях с высокопроницаемыми коллекторами. Одним из таких эффективных методов является гидравлический разрыв пласта (ГРП). При проведении операции ГРП в призабойной зоне продуктивного пласта образуется разветвленная система дренирования за счет подачи под высоким давлением 
рабочей жидкости [1]. Опыт разработки многих известных месторождений УВ с коллекторами проницаемостью менее $5-10^{*} 10^{-3}$ мкм $^{2}$, показывает, что ГРП является практически единственным методом вовлечения таких запасов в разработку. К работе низкопроницаемых пластов предъявляются дополнительные требования, что в ряде случаев ставит под сомнение экономическую целесообразность проведения гидравлического разрыва пласта и существенно увеличивает риск неуспешности операции.

Значительная часть операций гидроразрыва проводится в нашей стране. На сегодняшний день в России более 50 \% скважин подвергается ГРП. Например, на месторождениях Западной Сибири проведено более 25 тыс. гидравлических разрывов пластов. С каждым годом значение ГРП, как в мировой, так и российской практике будет только возрастать. В свою очередь, технология и техника метода гидроразрыва пласта будет усложняться. Несмотря на огромный объем выполненных исследований по ГРП, в технологии данной операции много нерешенных научных задач. В настоящее время на месторождениях Западной Сибири в $80 \%$ случаях возникают осложнения при освоении скважин после проведения гидроразрыва пласта. Основная часть эксплуатационных скважин работает в условиях образования на забоях «продуктов» гидравлического разрыва пласта с частичным или полным перекрытием интервала перфорации. Ликвидация остатков геля из скважины является сложнейшей задачей.

По результатам промысловых наблюдений доказано, что обратный вынос проппанта из трещины в скважину максимален на этапе освоения скважин. Это обуславливает необходимость разработки новых прогрессивных технических средств для совершенствования методики освоения скважин после гидравлического разрыва пласта.

\section{Материалы и методы исследований}

Материалы исследования составили результаты проведения ГРП на месторождениях Западной Сибири в коллекторах средней и низкой проницаемости. Для решения проблемы закупорки перфоканалов неразложившимся гелем и сокращения сроков освоения после ГРП, были проведены многочисленные теоретические и аналитические исследования, с целью разработки комплекса устройств. Проведен литературный обзор и патентный анализ по исследуемой проблеме. Выполнена критика аналогов и разработаны более совершенные устройства для промывки перфоканалов и интервалов перфорации скважин от выносимого из трещины «ила» и разрушенного проппанта.

\section{Результаты исследований и их обсуждение}

Вынос проппанта в скважину приводит к поломке электроцентробежного насоса, снижению продуктивности скважины, изоляции про- 
дуктивных пластов, частым промывкам забоев скважин. Известны многочисленные случаи, когда проппант выносится из трещины гидроразрыва пласта в огромных количествах, что существенно снижает потенциальные возможности продуктивных пластов. Количество проппанта и его разрушившихся частиц, поступающих в ствол скважины вместе с потоком пластового флюида, механических частиц и неразложившегося геля, максимально на этапах ее освоения и начальной эксплуатации Изображение ствола скважины в интервале перфорации после кольматации неразложившимся гелем с частицами проппанта показано на рисунке 1.

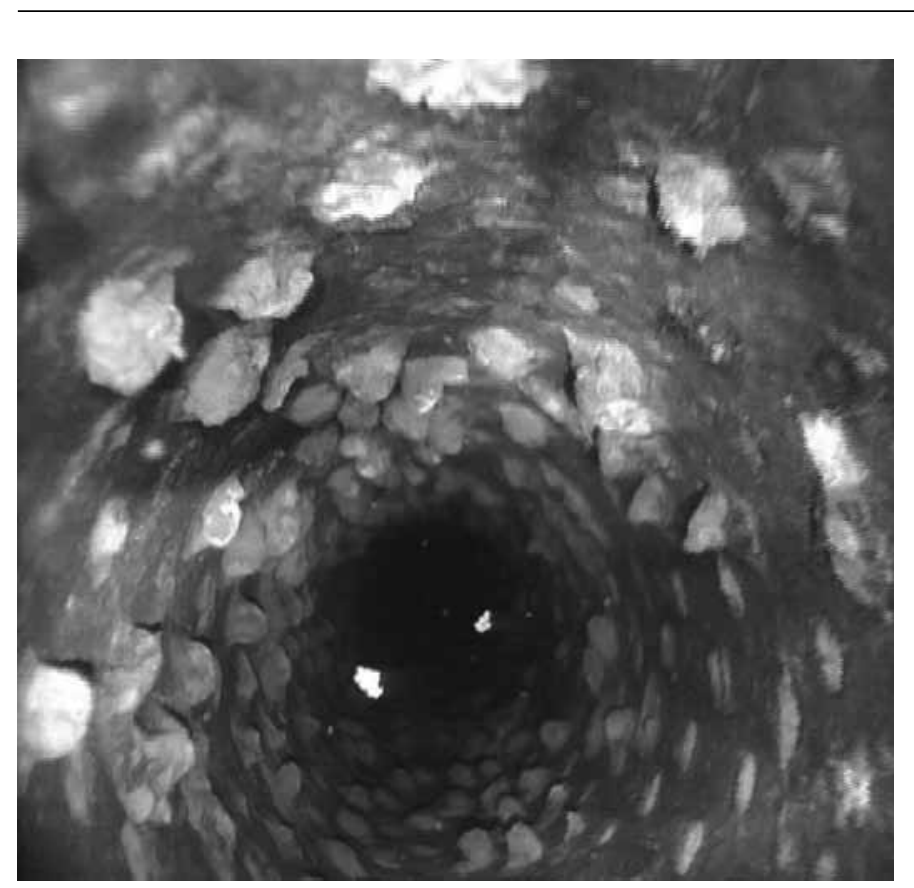

Рис. 1. Ствол скважины в интервале перфорации после кольматации.

Fig. 1. Wellbore wall in the perforation interval after formation damage.

Необходимо также отметить, что при плохом цементировании скважины, во время проведения гидравлического разрыва пласта часть проппанта заходит в пустоты в цементном кольце, а при освоении оттуда выносится. Помимо оседания геля на стенках скважины, данная химическая жидкость оседает также в перфоканалах, закупоривая их (рис. 2).

Специалисты нефтегазовой отрасли считают, что некоторая часть несущей жидкости не разрушается даже под воздействием современных деструк- 
торов - добавок, которые способствуют контролируемому снижению вязкости жидкости разрыва и удалению ее из трещины ГРП [2-5]. Если вязкоупругие «островки» остаются внутри трещины на длительное время, то они затвердевают. В дальнейшем эти участки трещины будут иметь пониженную проницаемость и отрицательно влиять на производительность скважины после выполнения ГРП [8]. Твердые и вязкоупругие частички деструктора также попадают в перфорационные каналы и налипают на стенки скважины. Эти отложения снижают проницаемость в перфоканалах. Чтобы улучшить производительность таких скважин необходимо применять промывку с максималь-

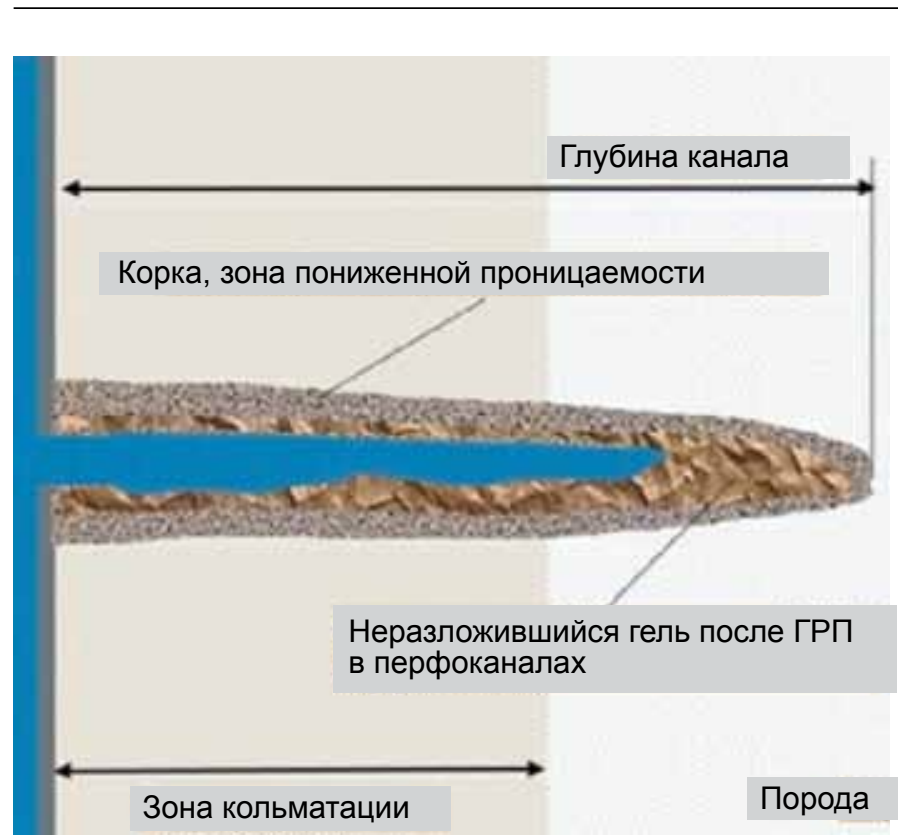

Рис. 2.

\section{Кольматация перфоканалов неразложившимся} гелем ГРП.

Fig. 2. Clogging of perforation channels by undecomposed gel for hydrofracturing.

ным приближением к осложнению. Избавиться от таких зон можно с помощью устройства для декольматации скважин, которое показано на рисунке 3.

Устройство состоит из корпуса 1 с цилиндрическим осевым каналом 2, перекрытым сверху переходником 3 с глухим донышком 4 с коническим выступом 5 , выходящим в цилиндрический осевой канал 2 , переходящий в конический осевой канал 6 , угол образующей которого равен углу наклона конического выступа 5. В теле переходника 3 над глухим донышком 4 выполнено 


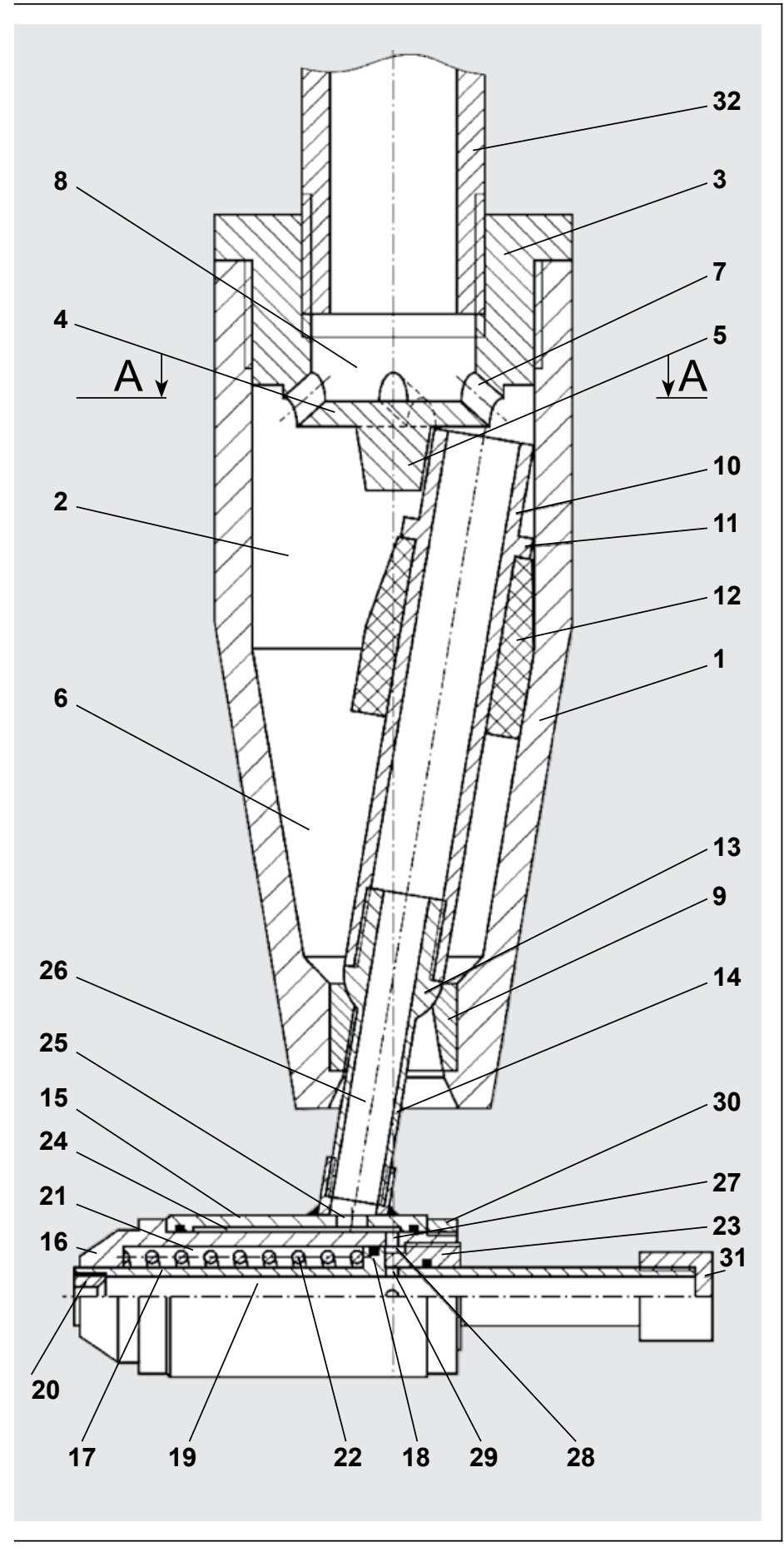

Рис. 3.

Конструкция устройства в разрезе, в исходном положении деталей (продольный разрез).

Fig. 3. The design of the device in section, the parts are in the initial position (long section). 
несколько тангенциальных каналов 7 , гидравлически соединяющих осевой канал 8 переходника 3 с цилиндрическим осевым каналом 2 корпуса 1 (рис. 3). На нижнем конце корпуса 1 выполнена расточка, в которой установлено опорное седло 9. Внутри осевых каналов, цилиндрического 2 и конического 6 размещен полый патрубок 10, снабженный кольцевым выступом 11, на который опирается упорная втулка 12 , установленная с возможностью контакта с внутренними поверхностями конического 6 и цилиндрического 2 осевых каналов корпуса 1. Верхний конец полого патрубка 10 расположен свободно между внутренней стенкой цилиндрического осевого канала 2 корпуса 1 и коническим выступом 5. На нижнем конце полого патрубка 10 установлен торцовый клапан 13 со сферической поверхностью, с опорой на ответную сферическую поверхность в опорном седле 9. При этом торцовый клапан 13 снабжен подающей трубкой 14, проходящей через осевой канал опорного седла 9 и связанной с гильзой 15 , охватывающей стакан 16 . В осевом канале стакана 16 установлена дренажная трубка 17, снабженная кольцевым выступом 18, в осевом канале 19 которой установлена насадка 20. Между дренажной трубкой 17 и внутренней поверхностью стакана 16 образована кольцевая камера 21, в которой размещена пружина 22, поджимающая кольцевой выступ 18 дренажной трубки 17 к торцу гайки 23, связанной со стаканом 16. В гильзе 15 выполнена внутренняя кольцевая расточка 24, которая связана перепускным отверстием 25 с осевым каналом 26 подающей трубки 14 и отверстиями 27 в теле стакана 16 с его осевым каналом 28 между гайкой 23 и кольцевым выступом 18 дренажной трубки 17, в теле которой выполнены радиальные отверстия 29 для гидравлической связи осевого канала 28 стакана 16 с осевым каналом 19 дренажной трубки 17 и находящиеся в исходном положении под гайкой 23. Стакан 16 зафиксирован в гильзе 15 стопорной гайкой 30. Осевой канал 19 дренажной трубки 17, выходящей за пределы стакана 16 перекрыт заглушкой 31 . В теле переходника 3 выполнена резьба для подсоединения к колонне гибких труб 32 колтюбинговой установки. Кольцевая расточка 24 в гильзе 15 защищена от попадания агрессивных сред уплотнителями 33 и 34. Кольцевой зазор между дренажной трубкой 17 и стаканом 16 изолирован уплотнителем 35, который установлен на кольцевом выступе 18. Кольцевой зазор между гайкой 23 и дренажной трубкой 17 перекрыт уплотнением 36. Принцип действия устройства описан в работе [9].

\section{Работа устройства}

Через резьбу в переходнике 3 осуществляют подсоединение к нижнему концу колонны гибких труб 32 колтюбинговой установки и вводят в скважину с допуском до расчетной глубины. Осуществляют подачу под давлением промывочной жидкости в осевой канал 8 переходника 3, откуда жидкость по тангенциальным каналам 7 в теле переходника 3 подается с вращением потока в осевой цилиндрический канал 2 корпуса 1. Направ- 
ленный динамический напор потока промывочной жидкости воздействует на площадь сечения полого патрубка 10 и упорной втулки 12, которая обкатывается по внутренней поверхности конического канала 6 корпуса 1. При этом конический выступ 5 на глухом донышке 4 играет роль направляющего ограничителя для верхнего конца полого патрубка 10, обеспечивая его движение по окружности, ограниченной образующей цилиндрического осевого канала 2 и поверхностью конического выступа 5. При этом торцовый клапан 13 на нижнем конце полого патрубка 10 своей сферической поверхностью проворачивается в ответной сферической поверхности опорного седла 9 с сохранением герметичности осевого канала 6 корпуса 1 от внешней среды. При вращении полого патрубка 10 с упорной втулкой 12 внутри осевого канала 6 корпуса 1 промывочная жидкость поступает в полый патрубок 10 и далее через перепускное отверстие 25 в теле гильзы 15 подается внутрь кольцевой расточки 24 , откуда через отверстия 27 в теле стакана 16 , в его осевой канал 28 , с воздействием на площадь кольцевого выступа 18 дренажной трубки 17. Под действием перепада давления дренажная трубка 17 с кольцевым выступом 18 отходит от торца гайки 23 с открытием подачи через радиальные отверстия 29 в теле дренажной трубки 17 в ее осевой канал 19. Дренажная трубка 17 перемещается внутри осевого канала 28 стакана 16, с выходом за его пределы в направлении к обрабатываемой поверхности с одновременным сжатием пружины 22. Струя промывочной жидкости истекает через канал насадки с воздействием на слой отложений, при нахождении от него на минимальном расстоянии. При постоянной подаче промывочной жидкости происходит вращение сборки относительно обрабатываемой поверхности. По мере очистки стенки трубы осуществляют плавное перемещение устройства вверх или вниз движением гибкой трубы колтюбинговой установки. После прекращения подачи промывочной жидкости усилием пружины 22 дренажная трубка 17 с кольцевым выступом 18 перемещается в осевом канале 28 стакана 16 до торцового контакта с гайкой 23 , с перекрытием сечения радиальных отверстий 29 и прекращением гидравлической связи осевого канала 19 дренажной трубки 17 с внутренней полостью устройства. При необходимости, для обеспечения более надежного возврата дренажной трубки 17 в исходное положение усилием сжатой пружины 22, возможна установка дополнительной пружины между гайкой 23 и заглушкой 31.

Применение данного устройства позволит увеличить эффект воздействия струи рабочего агента на отложения за счет использования ее полного расхода, который направляется через сопло, а также изолировать внутреннюю полость устройства от попадания пластовой жидкости и частиц разрушенного проппанта по окончании процесса промывки. Схема расположения устройства в скважине показана на рисунке 4. Технологической особенностью данного устройства является то, что его можно спускать через насоснокомпрессорные трубы с применением колтюбинговой установки. 


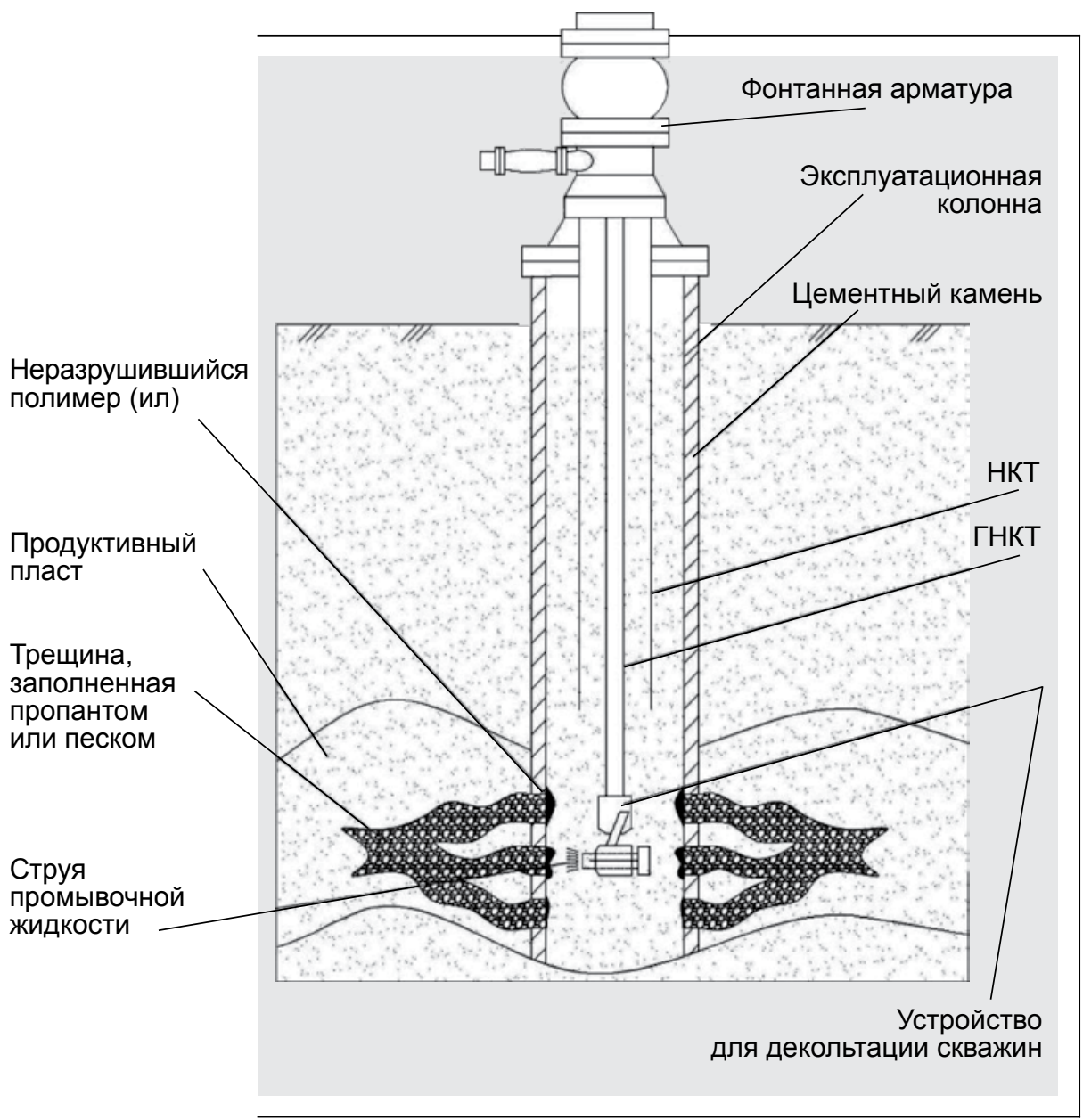

Рис. $4 . \quad$ Схема расположения устройства в скважине.

Fig. 4. Diagram of the device placement in a wellbore.

Таблица 1.

ТЕХНИЧЕСКИЕ ХАРАКТЕРИСТИКИ УСТРОЙСТВА

Table. 1 Technical specifications of the device

\begin{tabular}{ll}
\hline Расход жидкости через компоновку л/мин & 70-110 \\
\hline $\begin{array}{l}\text { Давление рабочей жидкости, не более, } \\
\text { Ма }\end{array}$ & 66 \\
\hline $\begin{array}{l}\text { Максимальный диаметр компоновки, } \\
\text { мм }\end{array}$ & 70 \\
\hline Рабочая жидкость & Вода \\
\hline Диаметры ГНКТ & 50,8 и 25,4 \\
\hline $\begin{array}{l}\text { Рабочая температура установки, } \\
\text { не более }{ }^{\circ} \mathrm{C}\end{array}$ & 145 \\
\hline
\end{tabular}




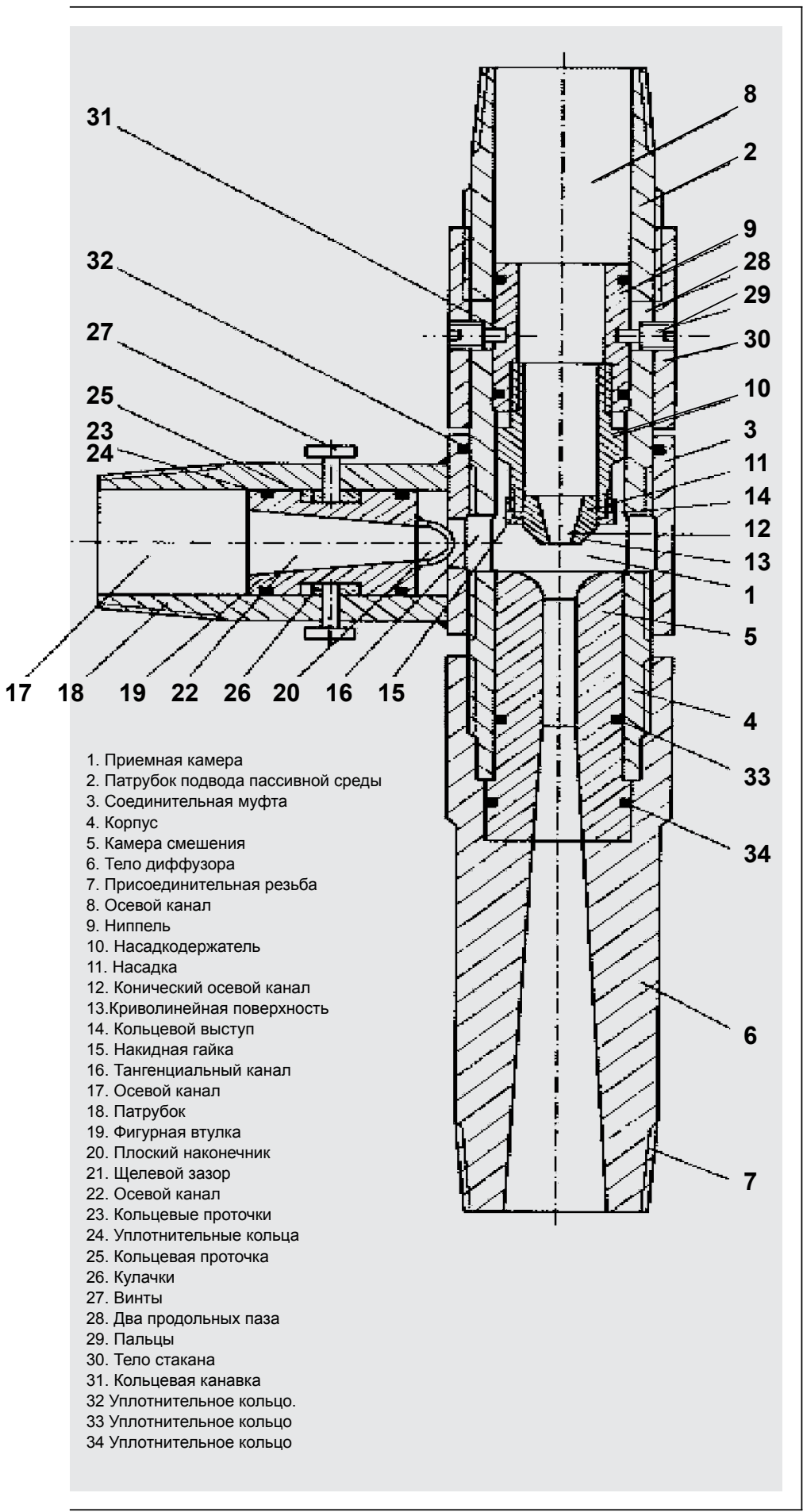

Рис. $5 . \quad$ Струйный насос.

Fig. 5. Jet pump. 
На месторождениях Западной Сибири все большее распространение находят гибкие насосно-компрессорные трубы (ГНКТ) для ликвидации в стволе скважины «продуктов» гидравлического разрыва пласта, которые выпадают на забой. Для промывки скважины предлагается использовать пенные системы.

Использование пенных систем обусловлено преимуществами:

- при попадании в пласт технологических жидкостей сохраняются коллекторские свойства призабойной зоны пласта (ПЗП);

— п пименение пенных систем позволяет быстро регулировать давление на забое скважины, таким образом можно оперативно перейти от репрессии к депрессии;

- пена обладает отличной несущей способностью, что улучшает очистку интервала перфорации от частичек геля и проппанта после ГРП.

Однако использование в качестве циркулирующего агента в скважине пенных систем сопровождается повышенной сложностью. Необходимо использовать специальное оборудование, чтобы создавать пену. Для лучшей генерации пены автором разработана конструкция струйного насоса. Схема струйного аппарата представлена на рисунке 5.

Струйный насос состоит из приемной камеры 1 , образованной патрубком подвода пассивной среды 2 , соединительной муфтой 3 , связанной с корпусом 4, в осевом канале которого установлена камера смешения 5, охватываемая снизу телом диффузора 6, с присоединительной резьбой 7 под быстросъемное соединение для связи с потребителем. В осевом канале 8 патрубка подвода пассивной среды 2 установлен с возможностью осевого перемещения ниппель 9, связанный с насадкодержателем 10, на нижнем конце которого установлена насадка 11 пассивной среды с коническим осевым каналом 12 и наружной криволинейной поверхностью 13. Насадка 11 снабжена кольцевым выступом 14 и свободно входит в осевой канал насадкодержателя 10, где удерживается от выпадения накидной гайкой 15. Насадка 11 размещается в приемной камере 1 , которая через тангенциальный канал 16 в теле соединительной муфты 3 гидравлически связана с осевым каналом 17 патрубка 18 подвода активной среды. В осевом канале 17 патрубка 18 установлена фигурная втулка 19 с коническим плоским наконечником 20, входящим внутрь тангенциального канала 16 с образованием щелевого зазора 21. Внутри фигурной втулки 19 выполнен подводящий осевой канал 22, гидравлически соединяющий осевой канал 17 патрубка 18 со щелевым зазором 21. На внешней стороне фигурной втулки 19 выполнены кольцевые проточки 23 для установки уплотнительных колец 24 и кольцевая проточка 25, в которой размещаются кулачки 26, снабженные винтами 27 для ограниченного осевого перемеще- 
ния фигурной втулки 19 в осевом канале 17 патрубка 18. В теле патрубка 2 для подвода пассивной среды выполнены два продольных паза 28, в которые введены пальцы 29, жестко связанные с телом стакана 30, охватывающим тело патрубка 2 подвода пассивной среды, и связанный с ним резьбовым соединением. Насадкодержатель 10 связан резьбой с ниппелем 9, снабженным на внешней стороне кольцевой канавкой 31 , в которую свободно введены концы пальцев 29. Кольцевой зазор между соединительной муфтой 3 и наружной поверхностью патрубка 2 для подвода пассивной среды герметизирован уплотнительным кольцом 32. Кольцевой зазор между наружной поверхностью камеры смешения 5 и корпусом 4 перекрыт уплотнительным кольцом 33. 3азор между камерой смешения 5 и диффузором 6 перекрыт уплотнительным кольцом 34.

\section{Принцип действия насоса}

Патрубок 2 подвода пассивной среды через быстросъемное соединение связывается с выкидной линией компрессора [11]. Патрубок 18 подвода активной среды подсоединяется к насосному агрегату. Активная среда подается в осевой канал 17 патрубка 18, откуда по подводящему каналу 22 втулки 19 подается по щелевому зазору 21 в тангенциальный канал 16 с выходом внутрь приемной камеры 1. При этом происходит закручивание потока, который по криволинейной поверхности 13 насадки 11 вводится в осевой канал камеры смешения 5 с изменением радиуса закрутки потока на меньший.

Поскольку насадка 11 установлена в насадкодержателе 10 свободно, то насадка 11 также может вращаться за счет взаимодействия с потоком. Согласно уравнению неразрывности потока при его закручивании с переходом на меньший радиус закрутки происходит увеличение его скорости со снижением давления в центре. Поток пассивной среды по коническому осевому каналу 12 насадки 11 втягивается в приемную камеру 1 и взаимодействует с активной средой, которая охватывает струю газа и сжимает ее. По мере перемещения смеси пассивной и активной сред происходит их смешивание с приобретением необходимой кинетической энергии и последующим ее преобразованием в потенциальную энергию давления при проходе через диффузор 7 с дальнейшей подачей смеси потребителю. Для оптимизации режима работы струйного насоса предусмотрено изменение расхода и скорости активной среды. Это достигается тем, что за счет передачи крутящего момента через винты 27 на кулачки 26, размещенные внутри кольцевой проточки 25 фигурной втулки 19, производится перемещение фигурной втулки 19 в осевом направлении. Тем самым конический плоский наконечник 20 вводится или выводится из тангенциального канала 16 с изменением сечения щелевого зазора 21 , а значит и скорости потока активной среды, подаваемой внутрь приемной камеры 1. Вращением стакана 30 относительно тела патрубка 2 при взаимо- 
действии пальцев 29 с телом ниппеля 9 по кольцевой канавке 31 осуществляют осевое перемещение ниппеля 9 вместе с насадкодержателем 10 и насадкой 11 внутри приемной камеры 1 с изменением расстояния между насадкой 11 и камерой смешения 5. При этом меняется режим работы струйного насоса. Такая настройка на оптимальный технологический режим работы струйного насоса может производиться непосредственно в процессе работы, остановки процесса и демонтажа устройства с места установки для перенастройки и изменения режима работы не требуется.

Применение данного струйного насоса для генерации пены позволит получить следующие преимущества, по сравнению с аналогичными устройствами:

- возможность управления технологическим процессом компримирования газа, получения аэрированных жидкостей (пенных систем) за счет осевого перемещения насадки относительно камеры смешения;

- возможность регулирования скорости подачи активной среды для оптимизации работы устройства за счет изменения живого сечения щелевого зазора путем перемещения фигурной втулки в осевом канале подводящего патрубка активной среды;

- возможность повышения эффективности смешения и компримирования двухфазных аэрированных жидкостей за счет подачи пассивной среды по осевому каналу приемного патрубка к насадке;

- возможность подачи активной среды через подводящий патрубок и щелевой зазор в камеру смешения перпендикулярно к оси насадки с завихрением в тангенциальных каналах, с изменением радиуса закрутки от большего диаметра к меньшему и падением давления в центре потока;

- возможность подсоса пассивной среды (газа) в воронку, образованную вращающейся активной средой (жидкостью), и их смешения.

\section{Выводы}

1. На нефтяных промыслах наблюдается выход из скважины больших объемов проппанта, механических частиц, неразложившейся жидкости гидроразрыва пласта. Некоторая часть несущей жидкости не разрушается даже под воздействием деструктора. Смесь механических частиц, обломков проппанта с неразложившемся гелем образует в перфорационных каналах и на стенках скважины трудноудаляе- 
мую смесь - «ил». В дальнейшем эти затвердевшие остатки снижают проницаемость в перфоканалах. Чтобы улучшить производительность таких скважин, необходимо ее промыть с максимальным приближением к осложнению. Избавиться от таких осложнений можно с помощью предлагаемого комплекса устройств, используемых для освоения скважин после гидроразрыва пласта.

2. Разработано устройство для декольматации скважин: Патент Российской Федерации на изобретение № 2651869, заявка № 2017109500.

3. Разработан струйный насос для лучшей генерации пены: Патент Российской Федерации на изобретение № 2643882, заявка № 2017114222.

\section{Библиографический список}

1. Верисокин А.Е., Граб А.Н., Граб Д.Н., Сериков Д.Ю. Анализ факторов, влияющих на работоспособность пакеров при проведении гидроразрыва пласта// Строительство нефтяных и газовых скважин на суше и на море. 2017. № 7.

2. Зинченко И.А. и др. Применение гидроразрыва пласта для интенсификации притока на газоконденсатных скважинах Ямбургского месторождения и перспективы применения метода в процессе дальнейшего освоения залежей. М.: ООО «ИРЦ Газпром», 2007.

3. Anderson J. Simpson M. and Bosinski P. Producing Natural Gas from Coal. Oilfield Review, Autumn 2003.

4. Reducing Produced Water Volumes from Coal Bed Natural Gas in the Powder River Basin. ALL, 2005.

5. Кейбал А.В., Кейбал А.А. О причинах обратного выноса проппанта в ствол скважины после гидроразрыва продуктивного пласта// Бурение и нефть. 2009. № 11.

6. Меркулов А.А. Импульсные технологии интенсификации и гидроразрыва пласта (часть I) // Нефтяное хозяйство. 2007. № 9.

7. Судо Р.М. Разработка низкопроницаемых пластов на месторождениях ОАО «РИТЭК» с применением гидроразрыва пласта // Нефттяное хозяйство. 2007. № 3.

8. Фахретдинов Р.Н., Бровчук А.В. Результаты применения гидроразрыва пласта для разработки южной лицензионной территории Приобского нефтяного месторождения // Нефртяное хозяйство. 2007. № 3.

9. Заявление о выдаче патента Российской Федерации; Регист- 
рационный номер № 2017109500, 18.04.2017; Устройство для декольматации скважин.

10. Верисокин А.Е., Машков В.А., Зиновьева Л.М. Восстановление добывных возможностей горизонтальных участков скважины путем удаления проппантовых пробок // Наука. Инновации. Технологии. Вып. № 4. 2015, Ставрополь, с. 81 - 90.

11. Заявление о выдаче патента Российской Федерации; Регистрационный номер № 2017114222, 24.04 2017; Струйный насос.

\section{References}

1. Verisokin A.E., Grab A.N., Grab D.N., Serikov D.U. Analysis of factors affecting the working capacity of packers during hydraulic fracturing // Stroitel'stvo neftyanykh i gazovykh skvazhin na sushe i na more [Construction of oil and gas wells on land and sea]. 2017. № 7.

2. Zinchenko I.A. et al. The application of hydraulic fracturing to intensify the inflow of gas condensate wells in the Yamburgskoye field and the prospects for applying the method in the process of further development of deposits. Moscow: JSC «IRC Gazprom», 2007.

3. Anderson J. Simpson M. and Bosinski P. Producing Natural Gas from Coal. Oilfield Review, Autumn 2003.

4. Reducing Produced Water Volumes from Coal Bed Natural Gas in the Powder River Basin. ALL, 2005.

5. Keybal A.V., Keybal A.A. On the reasons for the reverse removal of proppant into the wellbore after hydraulic fracturing of the reservoir // Burenie i neft. 2009. №11.

6. Merkulov A.A. Impulse technologies for stimulation and fracturing (Part I) // Neftyanoe khozyaystvo [Oil industry]. 2007. № 9.

7. Sudo R.M. Development of low-permeability reservoirs at the fields of JSC "RITEK" with application of hydraulic fracturing // Neftyanoe khozyaystvo [Oil industry]. 2007. № 3.

8. Fakhretdinov R.N., Brovchuk A.V. The results of hydraulic fracturing application for the development of the southern licensed territory of the Priobskoye oil field // Neftyanoe khozyaystvo [Oil industry]. 2007. № 3.

9. Application for the grant of a patent of the Russian Federation; Registration number No. 2017109500, 18.04.2017; Device for cleanout of wells

10. Verisokin A.E., Mashkov V.A., Zinovieva L.M. Restoration of production capabilities of horizontal sections of the well by removing proppant plugs // Nauka. Innovacii. Tekhnologii. Issue. № 4. 2015, Stavropol, pp. 81-90.

11. Application for the grant of a patent of the Russian Federation; Registration number № 2017114222 24.04.2017; Jet pump. 
Публикация поступила в редакцию 12.05.2018 г.

Принята к публикации 26.08.2018 г.

\section{Сведения об авторах}

Верисокин Александр Евгеньевич - старший преподаватель кафедры разработки и эксплуатации нефтяных и газовых месторождений Института нефти и газа Северо-Кавказского федерального университета. ORCID https://orcid.org/0000-0001-6530-4126; ResearcherID: http://www.researcherid.com/rid/P-9519-2018. Номер телефона: 8-962-015-41-66

Электронная почта: verisokin.aleksandr@mail.ru

\section{About the author}

Verisokin Alexander Evgenievich - senior lecturer of the department of development and operation of oil and gas fields, Institute of oil and gas, North Caucasus federal university. ORCID https://orcid.org/0000-0001-6530-4126; ResearcherlD: http://www.researcherid.com/rid/P-9519-2018.

Telephone number: 8-962-015-41-66

E-mail: verisokin.aleksandr@mail.ru 